\title{
Configurações do espasmar em Os idiotas
}

EDNA FURUITI Escola de Comunicações e Artes-ECA / USP 


\section{Resumo}

Utilizando como objeto de estudo o filme Dogma \#2 - Os idiotas, integrante da Trilogia Coração de Ouro, de Lars von Trier, este artigo investiga posssibilidades de sentidos nas três diferentes configurações realizadas pela personagem Karen (Bodil Jørgensen) do "espasmar", manifestação do suposto idiota reprimido que todas as pessoas trariam em seu interior.

\section{Palavras-chave}

configuração, espasmar, reiteração, Dogma 95, Lars von Trier, Trilogia Coração de Ouro

\section{Abstract}

In Dogma \#2 - The idiots, part of the Heart of Gold Trilogy by Lars von Trier, the spassing is supposed to be the manifestation of a repressed inner idiot common to everyone. This article investigates the possibilities of senses in three different configurations of spassing by the character Karen (Bodil Jørgensen).

\section{Key words}

configuration, spassing, reiteration, Dogma 95, Lars von Trier, Heart of Gold Trilogy 


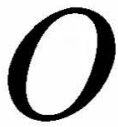

$s$ idiotas (Idioterne, 1998) é a segunda parte da trilogia Coração de Ouro de Lars von Trier, integrada ainda por Ondas do destino (Breaking the waves, 1996) e Dançando no escuro (Dancer in the dark, 2000). O filme é também resultado da obediência, mesmo que parcial, às regras estabelecidas pelo manifesto Dogma 95 idealizado juntamente com Thomas Vinterberg, de Festa de família (Festen, 1998). Em Os idiotas, Lars von Trier radicalizou as experiências de Ondas do destino, como a utilização da câmera na mão, a prioridade dada ao trabalho dos atores, a valorização da autenticidade das locações. Realizado com mini-câmeras digitais, Os idiotas também é uma experimentação de possíveis limites, preparação para a cinematografia manipulada de Dançando no escuro e as 100 câmeras da seqüência "Cvalda".

Sob o ponto de vista temático, o cerne do filme reside na oposição entre idiotia e normalidade: um grupo de amigos exercita em ambientes públicos e privados o que seria a manifestação de um idiota que todos trariam reprimido e latente dentro de si. Este binômio idiotia/normalidade é trabalhado de modo a evidenciar a sua ambigüidade, a zona limítrofe onde os opostos se confundem, se misturam. Esta mesma postura é adotada pelo filme em relação a uma outra oposição entre um cinema convencional e um outro, o cinema puro pregado pelo Dogma 95. A pertinência das discussões propostas pelo Dogma 95 é inerente ao próprio fazer cinematográfico: a construção da verdade e da verossimilhança, os suportes técnicos, as ideologias implícitas nos usos e manipulações dos recursos. No 
entanto, o impacto e a repercussão do manifesto sofreram diluição e declínio, resultado de sua própria superficialidade e radicalismo, da ironia de seu tom paródico e irreverente, do alarde de sua divulgação. Foram mais de trinta filmes de diferentes países como Bélgica, Suíça, Espanha, Itália, Estados Unidos, Coréia e Argentina que por se declararem obedientes às regras do manifesto receberam a chancela "filme dogma". Os filmes de Lars von Trier posteriores a Os idiotas - Dançando no escuro e Dogville (2003) - abandonam as propostas do manifesto, sem deixar de revelar questionamentos metalinguísticos como a construção da narrativa e da verossimilhança, a utilização dos recursos da linguagem cinematográfica. Após cinco anos desde a sua divulgação no Festival de Cannes de 1998, o Dogma 95 pode ser visto como uma moda volátil e descartável que passou, mas que por outro lado, exprimiu e reiterou a necessidade de renovação e de questionamento indissociável do fazer cinematográfico, postura que pode dialogar com aquela da Nouvelle Vague francesa.

O eixo fundamental de Os idiotas repousa na oposição e interação entre, por um lado, uma social e convencional normalidade e, por outro, a idiotia - o espasmar ${ }^{1}$ - manifestação de um idiota que todas as pessoas trariam reprimido dentro de si. $O$ foco de interesse estará dirigido aqui às configurações dadas ao comportamento espasmódico da protagonista Karen (Bodil Jørgensen), variação de Coração de Ouro, assim como Bess (Emily Watson) de Ondas do destino e Selma (Björk) de Dançando no escuro. "Coração de Ouro" conta a história de uma menina que entra em uma floresta ${ }^{2}$, com um pedaço de pão e algumas outras coisinhas no bolso. No

1. Utilizarei "espasmar" como uma versão em português dos termos utiliżados tanto pelo inglês ("spassing") quanto pelo espanhol ("hacer espasmos"). A versão brasileira em VHS utiliza "pirar", termo que sugere alheamento e devaneio, mas que se afasta de um entendimento mais interessante - como êxtase e enlevo, sugerido por "espasmo".

2. A imagem do mergulho na floresta escura pode ser compreendida como metáfora do auto-conhecimento, da descoberta de recantos e paisagens ocultas dentro de nós mesmos. O "mundo sem limite" mencionado por Bachelard é uma analogia da própria condiçāo humana, já que do conhecimento depende a referência, a nossa localização no mundo, a nossa inserção.

Por paradoxal que pareça, é freqüentemente essa imensidão interior que dá sua verdadeira significação a certas expressões referentes ao mundo 
caminho, ela se depara com diferentes situações e acaba por sair da escura floresta nua e sem mais nada. A menina, no entanto, não mostra qualquer ressentimento, sendo pelo contrário, plenamente confiante: "apesar de tudo, eu me saí bem"3. Ao final, a menina é recompensada por sua bondade e generosidade, tornando-se uma princesa. Karen é uma variação de Coração de Ouro que sofre distorção, em uma adaptação não tão evidente ou direta como em Bess ou Selma, nas quais a excepcionalidade do caráter da personagem Coração de Ouro é tomada de forma positiva e empática. A configuração de Karen é construída em complexidade evidenciando a precariedade da figura, o aspecto pejorativo da idiotia: por que Karen se junta ao grupo? Qual o sentido de seu sacrifício ao final do filme? Karen pode ser vista como síntese da ambigüidade do próprio filme, de suas contradições internas que comprometem a construção de sentido da narrativa, o entendimento de sua lógica intrínseca: por que os personagens prestam depoimentos? O que aconteceu posteriormente a Karen e Stoffer (Jens Albinus)? Por que os equipamentos aparecem em quadro? O diretor representa a ele mesmo ou a um outro quando faz as perguntas, as entrevistas?

Os idiotas é uma narrativa que propõe, como se pôde constatar, muitas perguntas e poucas repostas. Em seu formato episódico, também adota o procedimento da repetição para, no entanto, a cada vez obter resultados e decorrências díspares, distintas. A Coração de Ouro em Karen está perdida na escuridão e imensidão da floresta, e como ressalta Bachelard, nesta profundidade do mundo sem limites, se um não sabe para onde ir, não pode saber onde está. A primeira ocorrência do espasmar de Karen se dá no ambiente da casa: espaço sem móveis e então sem personalidade ou passado evidenciado, lugar de apropriação indevida e de efemeridade, abrigo múltiplo e

que se oferece à nossa vista. Para discutir um exemplo preciso, examinemos de perto a que corresponde a imensidão da Floresta. Essa "imensidāo" nasce de um corpo de impressões que não derivam realmente das informaçōes do geógrafo. Não há necessidade de permanecer nos bosques para conhecer a impressāo sempre um pouco ansiosa de que nos "aprofundamos" num mundo sem limite. Em breve, se não sabemos aonde vamos, não saberemos mais onde estamos. (Bachelard, 1978, p. 317)

3. "Preface", por Stig Björkman in Trier, 1996, p. 6. 
caótico. A casa dos idiotas é uma casa de neutralidade e de multiplicidade, casa que pode abrigar a idiotia e a normalidade e também a não-idiotia e a não-normalidade. É uma contraposição à casa de origem e ancestralidade, casa sem rastros do passado, onde os personagens são apresentados sem história. É nesta outra casa que a personagem encontra acolhida, uma recorrência do berço, $o$ nosso berço ancestral onde a segurança e a proteção podem ser absolutas.

(...) Sem ela [casa], o homem seria um ser disperso. Ela mantém o homem através das tempestades do céu e das tempestades da vida. Ela é corpo e alma. É o primeiro mundo do ser humano. Antes de ser "atirado ao mundo", como o professam os metafísicos apressados, o homem é colocado no berço da casa. E sempre, em nossos devaneios, a casa é um grande berço. Uma metafísica concreta não pode deixar de lado esse fato, esse simples fato, na medida em que esse fato é um valor, um grande valor ao qual voltamos em nossos devaneios. O ser é imediatamente um valor. $A$ vida começa bem; começa fechada, protegida, agasalhada no seio da casa. (Bachelard, 1978, p. 201)

Nesta casa vazia, a janela constitui o lugar do espasmar de Karen. Espaço de mirada, a janela é simultaneamente exterior e interior, local de transição, assim como os veículos da personagem Bess. A janela é também um recorte da realidade e da paisagem exterior, alusão ao próprio enquadramento cinematográfico. O recorte configurado pela janela, inserido no outro recorte mais amplo do enquadramento, apresenta ao fundo uma paisagem indefinida, quase abstrata (fig.1). Esta precariedade e indefinição da imagem resultam da opção pelo uso do vídeo digital e não se restringe ao fundo, mas atinge também a figura: a luz branca do exterior invade e se confunde com o contorno do rosto da personagem (fig.2). É justamente contra este fundo impreciso que se dará a primeira manifestação do espasmar da personagem que, por sua vez, também carece 
de definição, de contorno e separação. O limite é também perturbadoramente indefinido entre a "idiota interior" de Karen e a sua figura de normalidade construída até então, fazendo com que esta primeira manifestação seja permeada pela ambigüidade. A primeira ocorrência da idiotia não é voltada para os outros ou para o espectador, mas para um exterior, que em sua indefinição, pode se aproximar metaforicamente de seu contraponto, o interior, a interioridade, a subjetividade.

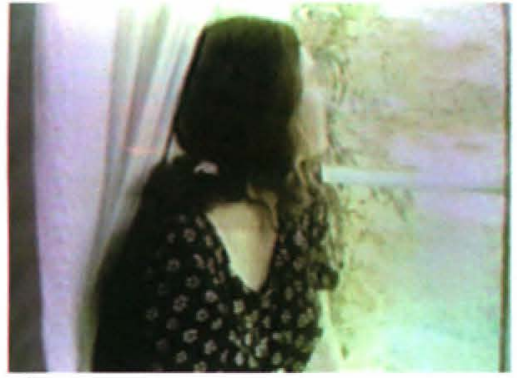

Figura 1

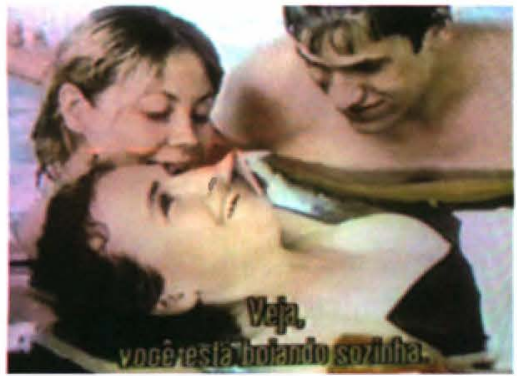

Figura 3

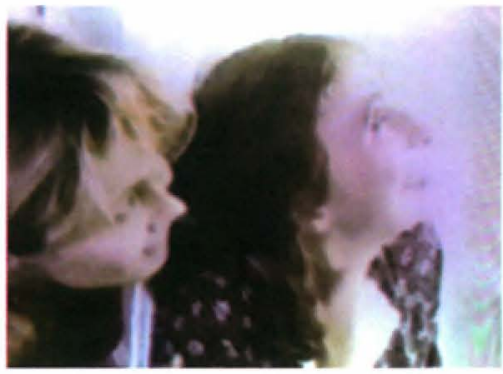

Figura 2

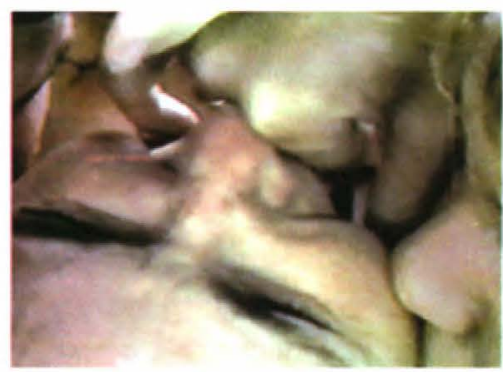

Figura 4

A interioridade é enfatizada na segunda ocorrência do espasmar na piscina (fig.3), na água - elemento purificador e maternal, símbolo da emoção e do inconsciente. Na água, o choro e a possibilidade de memória são possibilidades extáticas, somadas à manifestação anterior de contentamento. Na água, há o vestígio de um sofrimento ancestral e infinito - reminiscência de um trauma inerente à condição humana, trauma de nascimento, mas também de uma onipotência e eternidade inatingíveis. $O$ choro pode ser visto como possibilidade de arrebatamento e de catarse, resultado de uma 
experiência reveladora ${ }^{4}$ e da descoberta da idiotia como expressão ideal. Por outro lado, também pode apenas constituir um choro minimizado e mais cotidiano, ligado à informação da perda do filho dada no final do filme. A imersão da personagem é a amálgama desta multiplicidade de sentidos, sintomática de uma condição uterina que, efêmera, deverá ser rompida - uma necessária transição entre morte e renascimento. A câmera reflete também esta imersão e usa o close para fragmentar o rosto (fig.4), para penetrar na expressão da personagem, como se em busca de uma interioridade inacessível.

A água é realmente o elemento transitório. É a metamorfose ontológica essencial entre o fogo e a terra. $O$ ser votado à água é um ser em vertigem. Morre a cada minuto, alguma coisa de sua substância desmorona constantemente. A morte cotidiana não é a morte exuberante do fogo que perfura o céu com suas flechas; a morte cotidiana é a morte da água. A água corre sempre, a água cai sempre, acaba sempre em sua morte horizontal. Em numerosos exemplos veremos que para a imaginação materializante a morte da água é mais sonhadora que a morte da terra: o sofrimento da água é infinito. (Bachelard, 1989, pp. 6-7)

De maneira análoga a Ondas do destino, a última ocorrência do espasmar da personagem Karen ganha maior amplitude e intensidade porque foi precedido por uma outra significativa ocasião de falha, de irrealização. A desistência da personagem ocorre durante a festa, quando a proposta de sexo grupal, de suruba, ganha consistência pela adesão do restante do grupo. A suruba adquire a

4. A experiência de isolamento realizada para as gravaçōes e declaraçōes irônicas, como a citada abaixo, levam a questionar se a catarse possa ser da personagem ou da própria atriz:

Lars von Trier: Sim, creio que [fazer espasmos] é algo maravilhoso: algo que todo mundo deveria experimentar. Um dia sim, no outro não. $E$, de fato, muita gente o faz.

Richard Kelly: Para se refrescar.

LVT: Claro. É como uma ducha: uma ducha emocional. (Kelly, 2000, p.208) 
qualidade de prova, seja da adesão e comprometimento em relação ao grupo, ou da exclusão e verdadeira não-integração da personagem. A corporalidade de Karen evidencia a indecisão, a divisão entre a afirmação e a negação, através de uma duplicidade simultânea de direções: o corpo e a cabeça apontam para diferentes direções (fig.5). A personagem é então ausentada momentaneamente do relato, pois não é vista participando da suruba e nem é feita uma montagem paralela com uma outra possível ação simultânea. A tentativa de provar a integração foi apresentada como falha e incapacidade.

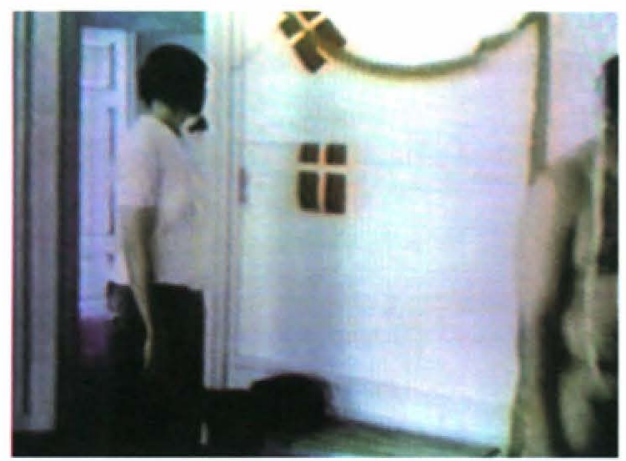

Figura 5

A terceira e última ocorrência do espasmar acontece com uma fundamental e determinante variação de lugar: na casa de origem e de família, contraposição à casa-berço e sua extensão - a piscina. A partir da variação de um elemento essencial, o deslocamento cronotópico, a idiotia pode ser constituída como singularidade e como tal, pode readquirir e re-presentificar o seu significado inicial e se descolar de suas variações anteriores que passam a constituir um fundo. A casa de idiotia, juntamente com o sentido readquirido pelo espasmar, passa simbolicamente também a configurar o fundo, enquanto a casa familiar pode se destacar como figura - casa habitada e populosa, que em meio à sua mobília, preserva ainda vestígios da anterioridade dos eventos, das emoçōes por eles causadas.

O espasmar de Karen utiliza elementos que dialogam diretamente com a figura, a casa de família: o lugar, a ocasião, o símbolo. A idiotia de Karen ocorre no sofá da sala de estar, ambiente de maior solenidade e formalidade da casa, lugar de dignidade e 
respeito, seja por parte daquele que acolhe, seja por aquele que é acolhido. A sala é a síntese de seus habitantes que pode ser externada e exibida, destituída da intimidade ou dos vestígios das roupas ou dos objetos de toalete. Apesar de utilitária e integrativa, é evidente e consciente a função da sala como espelhamento, como constituição de uma imagem, de uma aparência. E é justamente durante um lanche da tarde que Karen exerce a sua "idiota interior", durante uma ocasião de integração e comunhão, reunião de todos os integrantes da família em torno da comida e da bebida. Karen come e baba o bolo, alimento similar ao pão, símbolo não somente do alimento, mas do alimento primeiro, do pão da vida. O desprezo ao alimento é uma

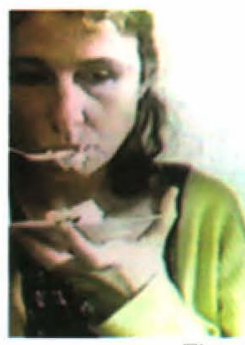

Figura 6

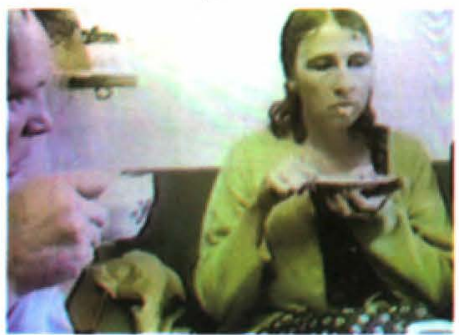

Figura 7

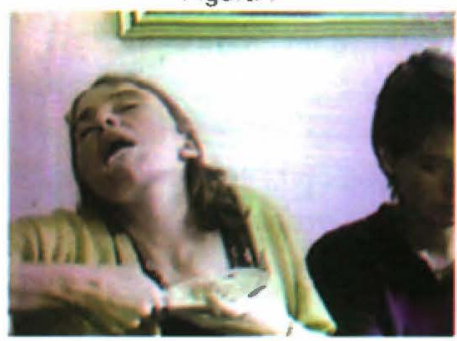

Figura 8

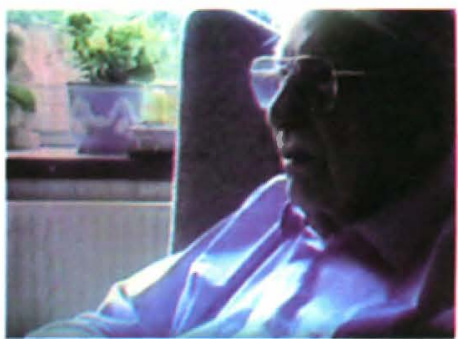

Figura 9

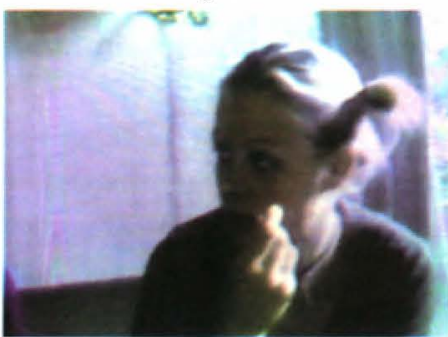

Figura 10

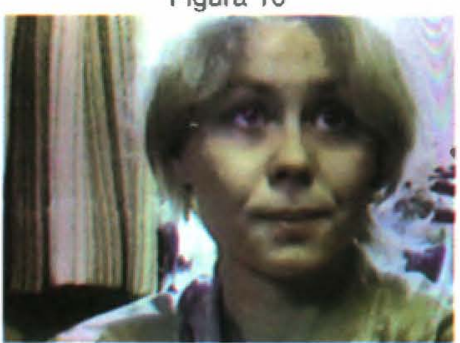

Figura 11 


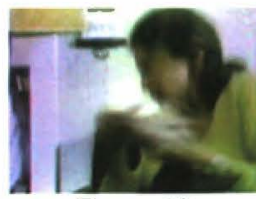

Figura 12

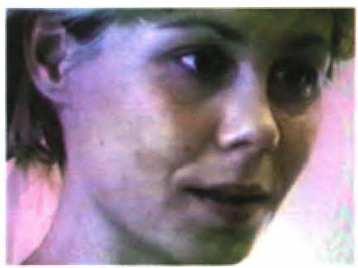

Figura 16

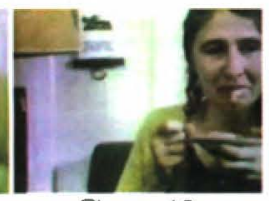

Figura 13

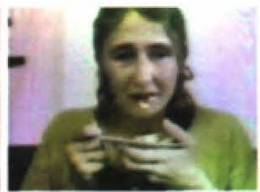

Figura 14

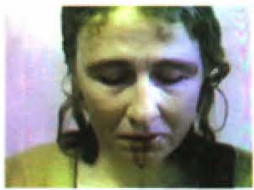

Figura 15

ofensa grave e universal, insulto à qualidade de sagrado do alimento, uma injúria à própria vida.

Figura 17

O sacrifício de Karen como configuração de variação de Coração de Ouro pode ser relacionado àquele empreendido por Selma através do assassinato de Bill (David Morse): é preciso praticar uma ofensa grave à vida, para que a própria vida e outros valores a ela relacionados possam ser exaltados e aprendidos pelos demais. A câmera em um primeiro momento está interessada na perspectiva do grupo: Karen é vista em um mesmo plano fixo, ora com o marido, ora com a irmã. O enquadramento favorece a simultaneidade entre ação e reação, mas como efeito secundário produz uma fragmentação que atinge algumas das figuras familiares - a irmã e o marido (figs.6-8), mas não o avô, a sobrinha ou Susanne (Louise Hassing) (figs.9-11).

A configuração de Karen durante o espasmar sugere que a ofensa não é dirigida somente aos outros, mas é também uma atitude de auto-imolação, de desmoronamento e deformação (figs.6-8). A personagem confirma o ato como martírio e auto-sacrifício que atinge seu ápice através do castigo, da punição pelo marido. $\mathrm{O}$ deslocamento causado pelo tapa, testemunhado e seguido pela câmera, pode ser corrigido para que gradualmente, a figura de Karen possa readquirir a propriedade e integridade do quadro (figs.12-15). A personagem passa a conformar uma figura centralizada e única, destacada e descolada do fundo, seja o fundo constituído pela casa dos idiotas ou pela anterioridade dos eventos. A configuração de Karen adquire finalmente contorno e limite, correspondência e equivalência em relação a um outro rosto, o de Susanne, com quem poderá partir (figs.16-17). 
Apesar da autonomia em relação às ocorrências anteriores, a configuração de Karen no último espasmar reitera o sentido essencial da imagem fundamental da personagem constituída através das variações no decorrer da narrativa: imagem de deslocamento, de estranhamento, de inadequação em relação ao ambiente e aos demais. Este efeito é também, no entanto, aplicado à família e à sua aparente normalidade. $\mathrm{O}$ vídeo digital, ao ser levado para dentro da casa, propicia uma forma de "contágio" da casa do grupo de idiotas, da multiplicidade a partir da co-existência, não necessariamente harmoniosa, entre idiotia, normalidade, não-idiotia e nãonormalidade. O digital, em sua espontaneidade e mobilidade, não é a priori adequado à casa de família e sua suposta normalidade, pois problematiza as figuras, colocando-as também sob um efeito de desvalorização, diminuição e indefinição (figs.18-20). Os enquadramentos e a precariedade da luz e da perspectiva podem não ser um efeito construído sobre a figura, mas sim, um efeito de revelação e desmascaramento involuntário e indesejado e, assim também, traumático em relação à absoluta segurança e proteção da casa de família ancestral.

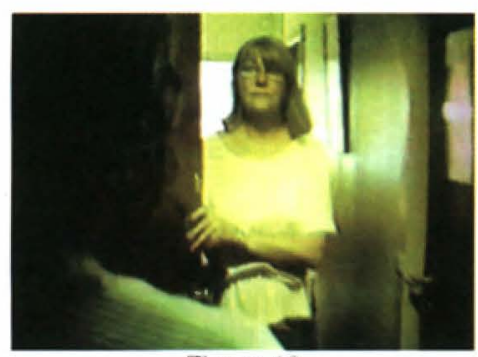

Figura 18

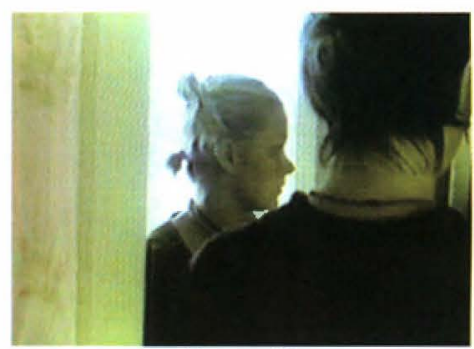

Figura 19

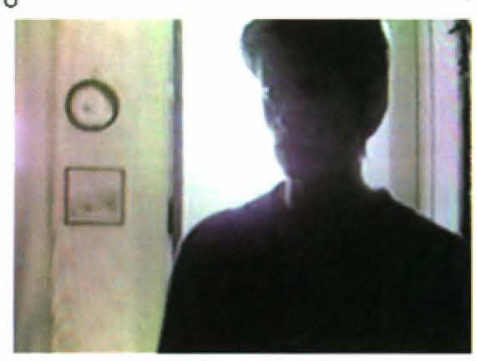

Figura 20 
A última ocorrência do espasmar pode ainda tangenciar o âmbito do traumático em relação ao enunciado pela intensidade e violência, mas especialmente, podè também ser relacionada ao traumático no âmbito da enunciação, ao poder ser compreendida como uma situação de síntese, de condensação da proposição fundamental da própria narrativa: uma postura de dualidade e de ambigüidade, construída em um jogo de negações e afirmações, de indicações e desvios, de falsas e efêmeras conclusões. Em uma perspectiva mais larga, este último conflito entre idiotia e normalidade é simbólico de um outro conflito mais amplo representado pelo Dogma 95 em relação a um paradigma cinematográfico convencional. Talvez não seja possível empreender este confronto sem prejuízo ou outros desdobramentos imprevistos, mas a alternativa a este paradigma pode residir menos na rigidez do "Voto de Castidade" e se aproximar mais de uma possibilidade de multiplicidade de sentidos e leituras. Em oposição a uma causalidade única e restrita dos eventos e de uma evidente e distintiva lógica norteadora da narrativa, pode haver uma coerência alternativa que abrigue também a ambigüidade e a dubiedade, como em Os idiotas.

\section{Bibiliografia}

BACHELARD, Gaston. 1978. A poética do espaço. São Paulo: Abril Cultural. (Coleção Os Pensadores).

1989. A água e os sonhos. São Paulo: Martins Fontes.

BJÖRKMAN, Stig. 2000. Lars von Trier - Entretiens avec Stig Björkman. Paris: Cahiers du Cinéma.

HEART OF GOLD. 1989. ilust. Rosalind White. Dharma Publishing, Oakland, California.

KELLY, Richard. 2000. El título de este libro es Dogma 95. Barcelona: Alba Editorial.

TRIER, Lars von. 1996. Breaking the waves. Londres: Faber and Faber. 
2000. Dancer in the dark - scénario bilingue. Paris: Cahiers du Cinéma.

VINTERBERG, Thomas. 2003. "Manifesto". Dogme 95 Official site. Disponível em www.dogme95.dk, fev.

.2003. "Voto de Castidade". Dogme 95 Official site. Disponível em www.dogme95.dk, fev. 